\title{
Women's Unpaid Work as a Factor of Gender Inequality: A Case of Kazakhstan
}

\author{
Yanovskaya OLGA*, Rajasekhara Mouly POTLURI**, Nazyrova GULFIYA***, Salimzhanova AIZHAN****
}

Received: May 10, 2019. Revised: December 14, 2019. Accepted: April 05, 2020.

\begin{abstract}
Purpose: This paper explores diverse issues related to the problem of women's unpaid domestic care work, and as a factor of gender inequality in their professional practice. Research Design: This article concentrated only on the analysis of secondary data available on the topic along with observation of facts in Kazakhstan based on diverse sources. In current conditions, the problem of women's unpaid domestic care work, and consequently, the lack of enough time and energy for professional employment. Distinguish domestic work vs. job/career/occupation, selffulfillment, education, and leisure has a significant impact on women's life satisfaction. Data, and Methodology: This article focuses only on secondary data available in different sources from which the researchers procures comprehensive data and information. Results and conclusion: A family policy that aims to promote combining maternity, and domestic work with paid employment is an effective way to increase the proportion of working mothers/women. It is crucial to not only proportionally distribute the household responsibilities in the family but also to form an effective mechanism of state support for women through the development of the social services sector, as well as the adoption of a system-wide approach to gender equality.
\end{abstract}

Keywords: Unpaid work; Gender policy; Labor participation; Unemployment; Gender equality.

JEL Classification Code: J12, J16, J21, J31, J64

\section{Introduction}

Domestic work in the family is an integral part of an individual's life and society. However, its contribution to the overall development of the social structure of society, social institutions, norms and rules, production of tangible and intangible goods has not yet been fully explored. Recently, there has been an increase in the importance of domestic work, forms of its management and classification

*Corresponding Author, Professor, advisor of the Independent Accreditation and Rating Agency, Astana city, Kazakhstan, Email: yanovskaya o@mail.ru

${ }^{\star *}$ Associate Professor in College of Business, Al Ghurair University, Dubai, United Arab Emirates, Email: rajasekhara.potluri@agu.ac.ae

${ }^{* * *}$ Candidate of Economics Sciences, assistant professor, Director of the Professional Center for Assessment and Certification of Qualifications, Astana city, Kazakhstan, Email: gylfia@mail.ru

****Ph.D. candidate in Economics of Istanbul Technical University, Director of the Scientific-research Institute of Social and Gender Studies at Kazakh State Women's Teacher Training University, Kazakhstan. Email: aizhan.salimzhan@gmail.com ๑ Copyright: Korean Distribution Science Association (KODISA)

This is an Open Access article distributed under the terms of the Creative Commons Attribution NonCommercial License (https://creativecommons.org/licenses/by-nc/4.0/) which permits unrestricted non- or specialization of women's activities in their homes, affecting both the family's private life and the development of society. Although we can observe that some families hire housekeepers to do domestic work, their number is insignificant. The increasing number of women in wage employment does not change the patterns of unequal distribution of domestic work between men and women, which largely predetermines the problem of gender inequality in society. In the system of national economy and statistics of the countries of the world, there is a concept of "invisibility" of domestic work. It refers to the fact that the contribution of women to the development of society remains undervalued. Unequal distribution of household responsibilities between spouses severely affected and distinguished by the dominant share of female labor and differentiate families depending on the contribution of partners to housework and their amount of leisure time (UNESCO, 2016). Research on the gender division of domestic work began relatively recently. Smith A., Bentham I. and Mill J.S., in their studies, paid attention to an economic aspect of the organization of labor and considered the spectrum of concepts such as working time, spare time, working day, and leisure, without taking into 
account the peculiarities of domestic labor division between men and women. There have been few studies about the economic benefits of social care services expansion, job creation, gender equality promotion through labor demand, and poverty reduction. Women do most of the unpaid domestic care work for the family, as compared to men, and choose types of employment that would keep the work and life balance which leads to high satisfaction and brings economic losses for the State. Today, the economy of Kazakhstan creates a nominal number of jobs than required, and more women are still waiting to get jobs in their respective fields. In the regions, the population growth and internal migration processes are not fully supported by social infrastructure (kindergartens, schools, hospitals, etc.), which affects the decent quality of life and women's life satisfaction. The main section of an article should start with an introductory section which provides more details about the paper's purposes, motivation, research methods, and findings. The introduction should be relatively nontechnical, yet clear enough for an informed reader to understand the manuscript's contribution.

\section{The international practice of gender differences}

There is a relationship between paid and unpaid labor. Countries with a high proportion of paid jobs (wage employment) in time use (China, Japan, and South Korea) tend to have a low percentage of unpaid work. The different situation takes place in the countries of Western Europe, Australia, New Zealand, and Turkey, where a large portion of such labor correlates with the time of paid work. As it was mentioned above, in all countries, a significantly larger share of unpaid work is done by women than by men. In states with the most substantial gender gap, men devote a minimum of time to household work. Less than one hour per day dedicated to household work by men in South Korea, India and Japan; 1.5 hours in China and South Africa; and almost 2 hours per day in Turkey, Italy, Mexico, Portugal, and Spain (IMF, 2013). The study of the structure of unpaid work shows that in all countries, women spend their time predominantly on outstanding work in the kitchen, and caring for children; whereas, men dedicate to outside paid employment. One of the reasons for the increase in unpaid work in the family is the birth of children, which increases the share of the domestic work of parents by $15-30 \%$.

There is a negative correlation between the amount of female unpaid work and their wage employment time. In countries with high female employment, the gender gap in time use on paid and unpaid work is minimal. In some countries, at the legislative level, women are entitled to shorter working days or part-time jobs, which is considered to be compensation for domestic work. Part-time work for women is standard in Australia, Germany, Japan, the Netherlands, and the UK, where more than $40 \%$ of women work part-time (OECD, 2005). The gender gap in the distribution of unpaid work is regulated and adjusted by the state when solving the problem of public policy. Transparent gender distribution of work characterizes Japanese society. Japanese men spend 59 minutes per day for housework, which is the lowest rate in comparison with other countries. In France, men spend 136 minutes in doing domestic work, 164 minutes in Germany, 103 minutes in Italy, 150 minutes in Great Britain, and 177 minutes in Sweden. The average for the Organization for Economic Co-operation and Development (OECD) countries is 131 minutes. In Europe, USA and Japan, women, spend twice as much time on the household and four times more on care for children than men. In OECD countries, women spend about 2.5 hours more per day on unpaid work than men, regardless of employment status (Reports of the Ministry of Social Affairs and Health, 2008).

In the European Commission report, it is noted that member states have made little progress in the provision of childcare services,-and that absence of childcare facilities is the main obstacle to the employment of women. In 2011, only ten member states reached the $33 \%$ of children's preschool coverage under the age of 3 years, and just nine countries reached the target level of $90 \%$ of children from 3 years to compulsory school age. The high cost of childcare services acts as a deterrent to employment (Ilkkaracan, Kim, \& Kaya, 2015). Apps and Rees (2004) have constructed a labor supply model, which shows that access to affordable childcare services, rather than conditional cash transfers for children, significantly increases the participation of women in the workforce and birth rate. In an empirical application, Apps and Rees (2005) analyzed that the time allotted by the women in Australia, the United Kingdom, and Germany declining to their professional work due to absence of public care services. This tendency leads to serious redistribution of particularly women's time between both domestic and professional practice and reduces the participation women's labor force participation.

In a comparative study, Boca and Sauer (2006) use a dynamic model of utility maximization to study the share of the involvement of married women in the labor force in France, Italy, and Spain. The less educated women in Italy and Spain dissatisfied with the institutional environment spread in their respective countries. If balanced and convenient environment spread, there would be a chance to increase labour force by $29.4 \%$, particularly from the women who have children under the age of three. According to Antonopoulos and Hirway (2010), a \$50 billion investment in the United States in the provision of 
social services for caring home-bound elderly and disabled people, as well as in childcare services, would create 1.2 million new jobs (more than $90 \%$ of those jobs would be for women), compared with 555 thousand new jobs created by equivalent investments in physical infrastructure $(88 \%$ of those jobs are for men).

For South Africa, Antonopoulos and Kim (2008) estimated that investment in the amount of $3.5 \%$ of government spending ( $1.1 \%$ of GDP) in social care services for home-bound elderly, as well as childcare services, would generate 772 thousand new jobs, and $60 \%$ of them would be for women. National growth would increase by $1.8 \%$ in favor of the poor: the income of the most reduced layers of the population would be increased by $9.2 \%$, poor households by $5.6 \%$. All this highlights the importance and prospects of more in-depth analysis and assessment of investment in social care services, as well as women's life satisfaction in Kazakhstan.

\section{Gender approaches in Kazakhstan}

The gender division of labor and the disproportionate burden of women in unpaid work defined as the source of systemic gender inequality and the gender gap in employment; the gender wage gap, horizontal and vertical segregation by gender; inadequate representation of women in politics and other social spheres and gender gaps in time use (http://site-to-you.ru/web/ref-200422.php). Due to family circumstances such as childbirth, and caring for children, the elderly and disabled people, women's employment rate is usually reduced. Women, especially mothers with young children, are classified as a group with low work capacity because they burdened with unpaid work in the family. The President of Kazakhstan Nazarbayev N. (2017) identified the improvement of the quality of human capital as one of the five priorities of the third modernization of Kazakhstan. In Kazakhstan, women are usually more educated than men, and there is the fact that educated women work more than women with a low level of education. OECD experts note the importance of human resources for Kazakhstan and consider this to be the primary source of the country's competitive advantages (OECD, 2016). The time of men usually consists of paid work and leisure time, while women are engaged in both paid work and unpaid work, such as housework, raising children and serving the needs of other family members. In Kazakhstan, employed women and men are confidently meeting the requirements at work. And as it comes to a family-household relation, the main burden of unpaid work falls on women, and women spend about 2 hours more on doing their domestic work, and in a daily time use, $25.4 \%$ of women's time is devoted to dealing with household work, while for men, it is $21.8 \%$. Within one year, the unpaid time is about two months (on average, 53 days) (Asian Development Bank, 2013). Dynamics of growth indicates a systemic character, so women have less rest and do not engage in self-development. Both parents should bear the same responsibility for the upbringing of children and housekeeping.

Kazakhstan's approach supposes the creation of conditions for expanding the opportunities for family development by achieving gender equality - a truly equitable relationship between a man and a woman, not only in the labor market but within each family. The Government of Kazakhstan successfully introduced legal mechanisms include maternity, paternity, and parental leaves along with other types of leaves related to family responsibilities, as well as the flexible use of the above said by reducing working hours. To strengthen the family institution, Kazakhstan's family policy contributes to improving access and quality of social services for families with children, and families with one parent, job creation with equal access and parental leave opportunities for both parents (single parents), eradication of poverty through an adequate wage levels, pensions and social benefits, and promoting the principles of shared responsibility of the family. In Kazakhstan, the existing legal mechanisms require new approaches that improve women's life satisfaction, work and life balance, and the expansion of social services.

The unemployment rate in Kazakhstan is significantly higher among women $(5.5 \%)$ is than for men $(4.4 \%)$. Despite the decline in the unemployment rate, in general, most women remain outside the labor market, and a significant proportion of the population is engaged in household work. Most of the times, women are less paid and sometimes unpaid in the labor market, which is more vulnerable and leads to discontentment (Human Development Report, 2016). In 2017, the number of unemployed in Kazakhstan was 442,300 people, and 237,000 of them were women $(53 \%)$. Most young women, who are considered to be economically active, are unemployed. The increase in the proportion of women who have not worked for more than one year has become a problem with negative economic and social consequences. Women's unemployment and non-participation in the labor market are two critical issues. Paid work is one of the vital components of the financial independence of women and their participation in society. Long-term unemployment leads to the fact that an active part of women not involved in the labor market, bears certain economic losses for the state. It is more difficult for women to find work because they are more involved in care work for children, and older adults in the family and are often involved in doing other household work. Unemployment has its negative 
consequences. And inactiveness in this area can lead to a decrease in the standard of living of the population, loss of educational potential, and a violation of the individual's right to self-determination.

Women under the age of 30 acquire a profession and improve their skills, while often simultaneously forming a family. Conflictual of these situations lead to a lag from men on the qualification level. This problem is solved by a decrease in the birth rate (Turner, 1992). Women's strive for lifelong learning, especially at the beginning of work, particularly in their profession, is less than for men. Hence, we can observe the less professional orientation of women. First professional training does not entirely solve the problem of equalization of qualifications.

Consequently, the role of retraining and advanced training for women in the work process, as well as in periods of separation from permanent employment is more involved. Professional retraining can become an instrument for involving women inactive life and have a significant impact on reducing unemployment and enhancing satisfaction with the experience. Strengthening the professional qualifications of women should take place during their working hours and be paid, which will have a positive impact on women's life satisfaction and will affect the results of the country's economic development. Gender gaps between women's educational training and labor force participation can be reduced by $50 \%$ by implementing effective institutional mechanisms. An integrated approach to implementation of the gender equality strategy and policy will identify barriers that prevent women from participating in economic and political life and formulate an effective system to eliminate imbalances and improve the standard of living for women. Despite the increased participation of women in the labor force, in most countries, they still carry most of the household work and do most of the unpaid work (Shelton, 1992). The role of women in the development of society cannot be overestimated. The contribution of women to the economy of the country and household income is significant. Today, some families in which women are responsible for the material support of the family are growing. Women's work does not receive evaluation either as a result of unequal pay for the same workload which is done by male colleagues, or as a result of restricting women's access to highly paid sectors of the labor market. It is necessary to solve the problem of reducing women's unpaid domestic work, distributing responsibilities among family members in doing housework Men and other family members need to be involved in doing household work, which will create conditions for increasing the level of women's life satisfaction.

It is essential to expand the social care infrastructure (additional coverage of children in preschool education, care for the elderly and disabled, and inclusive education), which will create new jobs. Most of these jobs, particularly in the case of expanding social care services, would be for women and would provide social security for women. Women involved in the children care services will be able to engage in the labor market actively. Social infrastructure is a macro-level example of gender budgeting and effective macroeconomic policy for sustainable growth. The creation of social Centers in Kazakhstan would help women to deal with unpaid care work and determine the need for expanding social care services. The establishment of the Centers for the development of adolescents, for the elderly and the disabled, ad for children with special needs has the potential to improve the quality of life of women, reducing the burden of unpaid work,-and promoting the employment of women. As a result, it would increase the level of consciousness of women's satisfaction. Expanding social care services can restore costs by increasing government revenue.

\section{Approaches to reducing the gender gap}

In Kazakhstan, it is necessary to form new approaches to improving family policy and gender equality, and improving the quality of family life by combining family responsibilities with work. There are some laws on gender equality in the Republic of Kazakhstan. However, conditions are not entirely harmonious, and there is no real effect. The existing mechanism of state measures for the social support of women, the strengthening of family values, and the development of economic opportunities for women, especially in rural areas, do not provide necessary conditions for women's life satisfaction and their involvement in the labor force. Professional training, retraining, and advanced training for women are becoming an important issue in society. Preparing women for new professions would help them to be involved in the labor market and lead to an increase in life satisfaction. The development of women's entrepreneurship and involvement in social work would improve the working and living conditions of women in the future. The relationship between the level of employment of women and fertility is generally recognized. The main reason for the fall in the birth rate, particularly in the working women's community is a heavy workload with nominal wages, which causes an increase in divorce rates. The number of divorces and single mothers is increasing in Kazakhstan. Solving the problems of employment will positively affect the strengthening of the family. Formation and development of the Centers for adolescents, the elderly and the children with special needs, would enable women confidently to resume their professional career as employees and entrepreneurs even in their old age to work actively. Such 
centers contribute to the education of youth, the transfer of knowledge and experience, and the provision of leisure for children and retired people. Establishment of the Centers in Kazakhstan does not require significant investments from the state, but would create additional jobs, reduce social tension, release the category of women involved in the upbringing of children and include them in the labor force, and solve problems of gender inequality. Full access to social services and effective policy of gender equality will increase women's life satisfaction in general. Ensuring the successful implementation of the strategy and quality policy for eliminating imbalances will improve the living standards of women and affect their life satisfaction and, in general, the socio-economic development of the country.

\section{Conclusion}

Effective mechanisms of gender equality should be aimed at the redistribution of the burden of women's unpaid work, equal distribution of household duties in the family, as well as the involvement of both women and men in domestic work. This will reduce the gap in the delivery of daily time use, increase the participation of women in the economic life of society, and bring benefits to the state. Ensuring the balance of work and personal life, the redistribution of responsibilities should occur through the creation of legal and institutional mechanisms of the country that will help to harmonize unpaid domestic work with labor activity and increase the women's life satisfaction. State policy and access to a decent part-time job could create the conditions for women to choose reconciliation of professional advancement and motherhood, and strengthen the gender approach.

\section{References}

Antonopoulos, R., \& Hirway I. (2010). Unpaid work and the economy: Gender, time-use, and poverty in developing countries. New York, NY: Palgrave MacMillan.

Antonopoulos, R., \& K. Kim. (2008). Impact of Employment Guarantee Programmes on Gender Equality and Pro-poor Economic Development. Policy Brief: Case Study on South Africa. Annandale-on-Hudson, NY: Levy Economics Institute of Bard College. January.

Apps, P., \& Rees R. (2004). Fertility, taxation, and family policy. The Scandinavian Journal of Economics, 106(4), 745-763.

Apps, P., \& Rees R. (2005). Time use and the costs of children over the life cycle. In D. Hamermesh \& G. Phann (Eds), The Economics of Time Use. London, England: Elsevier.

Asian Development Bank (2013). Country gender assessment: Kazakhstan. Retrieved September 08, 2019, from https://www.adb.org/documents/country-gender-assessmentkazakhstan

Boca, D. D., \& Sauer, R. M. (2006). Life cycle employment and fertility across institutional environments (IZA Discussion Paper No. 2285). Bonn, Germany: Institute for the Study of Labor. Retrieved September 08, 2019, from http://ftp.iza.org/dp2285.pdf

Career or family - a dilemma for a modern woman. (n.d.) Retrieved from http://site-to-you.ru/web/ref-200422.php

Human Development Report. (2016). Human development for everyone. Retrieved September 08, 2019, from http://hdr.undp.org/sites/default/files/2016_human_developme nt_report.pdf

Ilkkaracan I., Kim, K., \& Kaya T. (2015, August). The impact of public investment in social care services on employment, gender equality, and poverty: The Turkish case. Retrieved September 08, 2019, from http://www.levyinstitute.org/pubs/rpr_8_15.pdf

International Monetary Fund. (2013, September). Women, work, and the economy: Macroeconomic gains from gender equity. Retrieved September 08, 2019, from https://www.imf.org/external/pubs/ft/sdn/2013/sdn1310.pdf

Nazarbayev, N. (2017, January 31). Third modernization of Kazakhstan: Global competitiveness. Retrieved September 08, 2019, from http://www.akorda.kz/en/addresses/addresses_of_president/the -president-of-kazakhstan-nursultan-nazarbayevs-address-tothe-nation-of-kazakhstan-january-31-2017

OECD (2005). Babies and Bosses - Reconciling work and family life (Vol. 4). Paris, France: OECD Publishing. Paris, https://doi.org/10.1787/9789264009295-en.

OECD (2016, January 20). Multi-dimensional Review of Kazakhstan (Vol. 1). Retrieved September 08, 2019, from https://www.oecd.org/publications/multi-dimensional-reviewof-kazakhstan-9789264246768-en.htm

Reports of the Ministry of Social Affairs and Health (2008). Long careers? 'Veto' program indicators. Retrieved September 08, 2019 from https://julkaisut.valtioneuvosto.fi/bitstream/handle/10024/7440 5/Selv200827.pdf? sequence $=1$

Shelton, B. A. (1992). Women, men, and time: Gender differences in paid work, housework, and leisure. Westport, CT: Greenwood Press.

Turner, J. B. (1992). Review of workings of the household: A U.S.-U.K. comparison. Contemporary Sociology, 21, 247-249.

United Nations Educational, Scientific, and Cultural Organization (2016). Education for people and planet: creating a sustainable future for all (Global Education Monitoring Report). 